\title{
Paratactic Assembly of Two Distinct Units into a Unique 3D Architecture
}

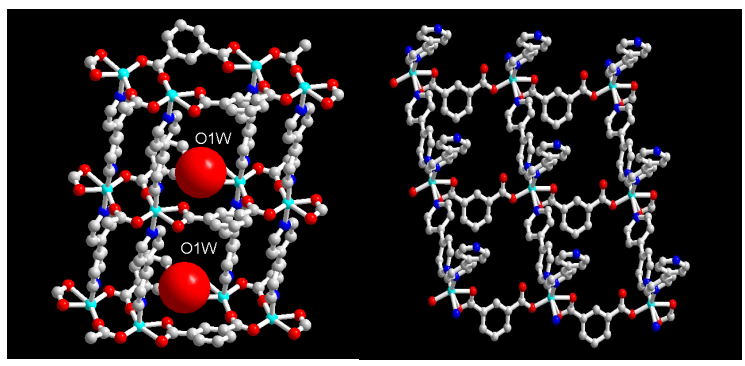

A

B

Fig. S1 (A) Polymer 1 with the guest water encapsulated inside the box-like cavity; (B) the table-like polymer $\mathbf{2}$.

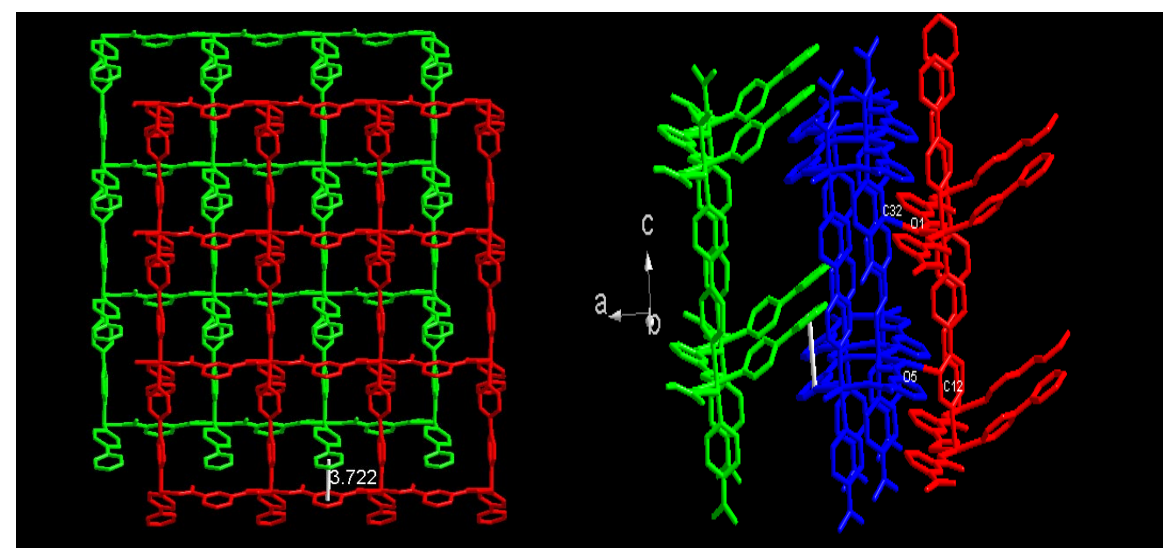

A

B

Fig. S2 (A) $\pi-\pi$ interactions between phenyl rings of ip and 4, 4-bipy between the two embedded tables of polymer 2; (B) the supramolecular interactions between $\mathbf{1}$ and $\mathbf{2}$ : $\mathrm{C} 12 \ldots \mathrm{O} 5=3.268(6) \AA, \mathrm{C} 32 \ldots \mathrm{O} 1=3.430(8) \AA ⿻ \mathrm{C} 12-\mathrm{H} 12 \ldots \mathrm{O} 5=155.9(4)^{\circ}$, $\mathrm{C} 32-\mathrm{H} 32 \ldots \mathrm{O} 1=165.6(4)^{\circ}$. 